\title{
HYBRID TECHNIQUE FOR KNOWLEDGE REPRESENTATION \& A COMPARATIVE STUDY
}

\author{
POONAM TANWAR ${ }^{1}$, DR. T. V. PRASAD ${ }^{2}$, DR. KAMLESH DATTA ${ }^{3}$ \\ ${ }^{1}$ Asst. Professor, Dept. of CSE, Lingaya’s University, Faridabad, Hryana, India \& PhD \\ Scholar, Uttarakhand Technical University, Dehradun, Uttarakhand, India \\ poonam.tanwarerediffmail.com \\ ${ }^{2}$ Dean (R\&D), Lingaya's University, Faridabad, Haryana, India \\ tvprasad2002@yahoo.com \\ ${ }^{3}$ Associate Prof \& HOD (CSE), National Institute of Technology, Hamirpur, \\ Himachal Pradesh, India \\ kdnith@gmail.co m
}

\begin{abstract}
Knowledge representation $(K R)$ and inference mechanism are most desirable thing to make the system intelligent. System is known to an intelligent if its intelligence is equivalent to the intelligence of human being for a particular domain or general. Because of incomplete ambiguous and uncertain information the task of making intelligent system is very difficult. The objective of this paper is to present the hybrid $K R$ technique for making the system effective \& Optimistic. The requirement for (effective \& optimistic) is because the system must be able to reply the answer with a confidence of some factor. This paper also presents the comparison between various hybrid KR techniques with the proposed one.
\end{abstract}

\section{KEYWORDS}

Knowledge Representation (KR), Semantic Net, Script, Krypton, Oblog 2, Mantra, Frorl.

\section{INTRODUCTION}

Knowledge representation: - In AI system implementation, efficiency, speed and maintenance are the major things affected by the knowledge representation. A KB structure must be capable of representing the broad spectrum of knowledge types categorized by Feigenbaum include [5].

- Objects - information on physical objects and concepts

- Events - time-dependent actions and events that may indicate cause and effect relationships.

- Performance - procedure or process of performing tasks

- Meta-knowledge - knowledge about knowledge including its reliability, importance, performance evaluation of cognitive processors. 
Many of the problems in AI require extensive knowledge about the world. Objects, properties, categories and relations between objects, situations, events, states and time, causes and effects are the things that AI needs to represents. Knowledge representation provides the way to represent all the above defined things [38]. KR techniques are divided in to two major categories that are Declarative representation \& Procedural representation. The Declarative representation techniques are used to represents objects, facts, relations. Whereas the Procedural representation are used to represent the action performed by the objects. The propositional logic, predicate logic, semantic net are the declarative knowledge representation techniques and Script, Conceptual dependency are procedural knowledge representation techniques. There is one more technique named frame that can be used as both. Each one has their own prone and cons. Now days because of market demands there are number of hybrid techniques are available. In next section we cover the few hybrid KR techniques.

\subsection{KRYPTON}

In 1983 Ronald J. Brachman, Richard E. Fikes, Hector J. Levesque has developed krypton a hybrid knowledge representation technique.

Technical description: Two boxes are used terminological box (T box) and assertion box (A box). TBox used the structure of KL-ONE in which terms are organized taxonomically, using frames an ABox used the first-order logic sentences for those predicates come from the TBox, and a symbol table maintaining the names of the TBox terms so that a user can refer to them. It is basically a tell ask module. All interactions between a user and a KRYPTON knowledge base are mediated by TELL and ASK operations shown in fig 1[14][16].

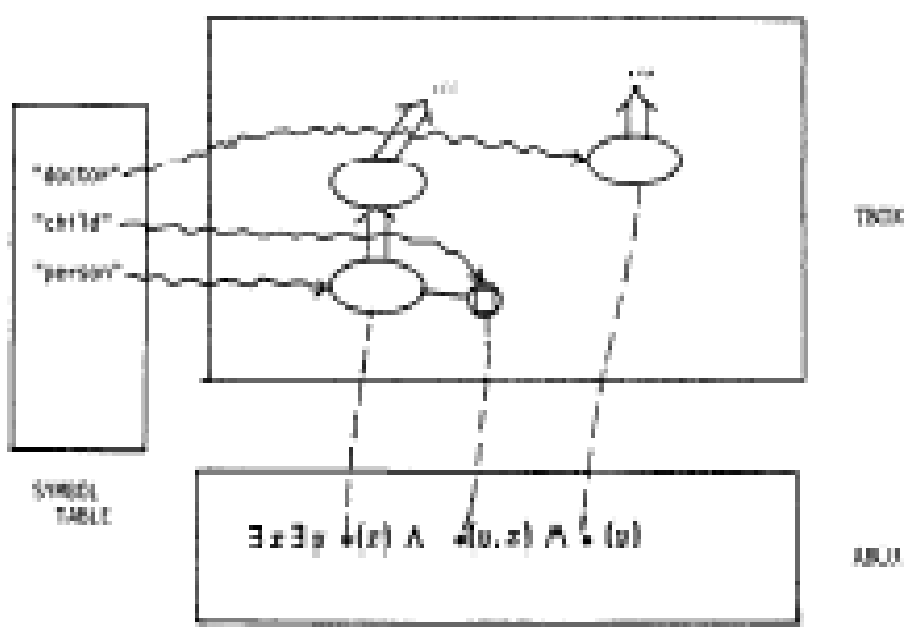

Fig.1 Overview of KRYPTON [14]

\subsection{OBLOG 2:-}

In 1987, Thhomas F. Gordon Presented the Oblog 2. Oblog stand for Object-oriented LOGic, is an experimental hybrid knowledge representation and reasoning system. It is a hybrid of a terminological reasoner with a Prolog inference mechanism. The description of type and attribute taxonomies are supported by terminological component whereas Entities are instances 
of a set of types. Horn clause rules are used as Procedures, \& for determining the values of attributes are indexed by type.

\subsection{MANTRA}

In 1991 MANTRA was developed by J. Calmet, I.A. Tjandra, G. Bittencourt.

Technical description: It is the combination of four different knowledge representation techniques. First order logic, terminological language, semantic networks and Production systems. all algorithm used for inference are decidable because this representation used the four value logic. Mantra is a three layers architecture model. It consist the epistemological level, the logical level, Heuristic level.

\subsection{FRORL:}

(frame-and-rule oriented requirement specification Language) was developed by Jeffrey J. P. Tsai, Thomas Weigert, Hung-Chin Jang in 1992.

Technical Description: FRORL is based on the concepts of frames and production rules Which is designed for software requirement and specification analysis. There are two types of frames Object frame and activity frames. Object Frames are used to represent the real world entity not limited to physical entity. These are act as a data structure. Each activity in FRORL is represented by activity frame to represent the changes in the world. Activity, Precondition and action are reserved word not to be used in specification. FRORL consist of Horn clause of predicate logic. The comparisons between various hybrid KR techniques with the proposed technique are shown in table 1.

\section{KNOWLEDGE BASE SYSTEM}

The KR system must be able to represent any type of knowledge, "Syntactic, Semantic, logical, Presupposition, Understanding ill formed input, Ellipsis, Case Constraints, Vagueness". In our previous paper we have proposed the model for effective knowledge representation technique that consist five different parts the K Box, Knowledge Base, Query applier, reasoning and user interface as shown in fig 2.The hybrid knowledge representation technique used here is the integration of script and semantic net KR technique. The semantic net \& script KR technique are explained in next subsection.

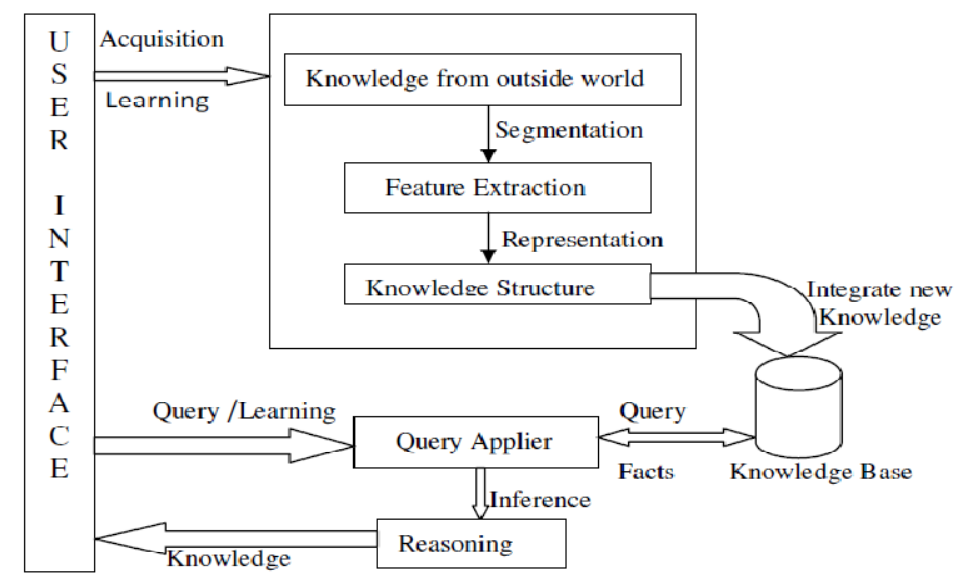

Fig 2. Knowledge Base System Model /Architecture[39]. 


\subsection{SEMANTIC NET}

A semantic network is widely used knowledge representation technique. Semantic network is a KR technique in which the relationship between class and objects are represented by the connection/link between objects or class of objects.

The nodes / vertices in semantic net are used to represent the Generic class or a particular class or an instance of a class (object).Relation between them is represented by the link, which shows the activation comes from where. The links are unidirectional these links represents the semantic relationship between the objects. Semantic network are generally used to represent the inheritable knowledge. Inheritance is most useful form of inference. Inheritance is the belongings in which element of some class inherit the attribute and values from some other class shown in Fig.3 [38].

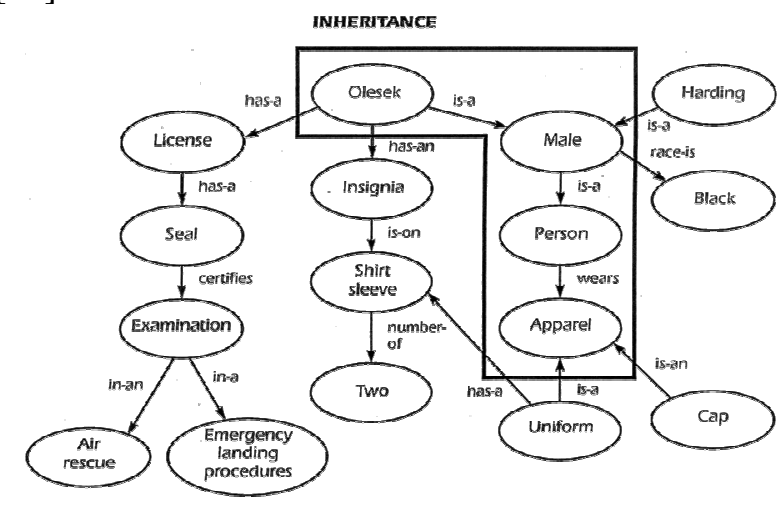

Fig.3 represents the inheritance relation [35][38].

Because there is an association between two or more nodes the Semantic nets are also known as associative nets. These associations are proved to be useful for inferring some knowledge from the existing one. If user wants to get any knowledge from the knowledge base they need not to put any query. The activated association or relation provides the result directly or indirectly only need to follow the links in the semantic net. IS-A, and A-KIND-OF are generally used to represent the value of a link in semantic net shown in fig 4.

$\mathrm{KR}$ techniques are divided in to two main categories one is declarative and other is procedural. Semantic net is a declarative KR technique that can be used either to represent knowledge or to support automated systems for reasoning about knowledge. Semantic net

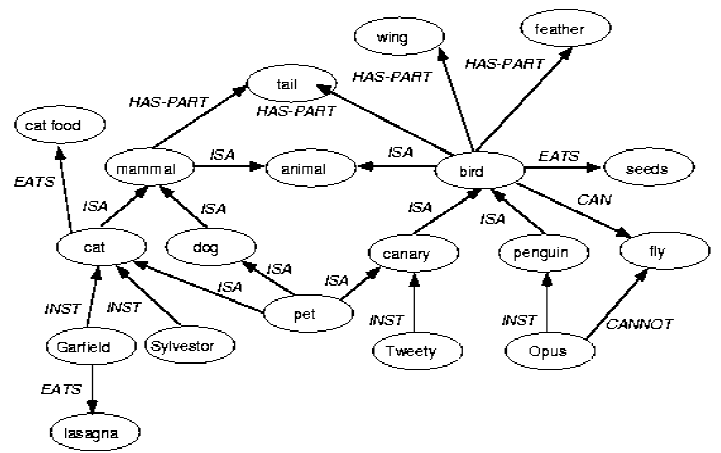

Fig 4 Represents of IS-A, HAS, INSTANCE [17], [38]. 
can be used in variety of ways, as per the requirement following are six of the most common kinds of semantic networks.

1. Definitional networks

2. Assertional networks

3. Implicational networks

4. Executable networks

5. Learning networks

6. Hybrid networks

During 1975 (See Walker ) Partitioned semantic net came in picture for speech understanding system. Then after that in 1977 Hendrix explained how we can expend the utility of semantic net using partitioned semantic net [8].In case of a huge network semantic net can be divided in to two more net. The semantic net is to be partitioned to separate the various nodes and arcs in to units and each unit is known as spaces. Using partitioned semantic net user can define the existence of the entity. One space is assigned to every node and arc and all nodes and arcs lying in the same space are distinguishable from those of other spaces. Nodes and arcs of different spaces may be linked, but the linkage must pass through the boundaries which separate one space from another [38].

Partitioning semantic nets can be used to delimit the scopes of quantified variables. While working with quantified statements, it will be help full to represent the pieces of information consist some event .For ex "Poonam believes that earth is round " is represented by the fig 5 . Nodes $<$ POONAM $>$ ' is an agent of Event node. $<$ EARTH $>$ ' and $<$ ROUND $>$ represent the objects of space1.

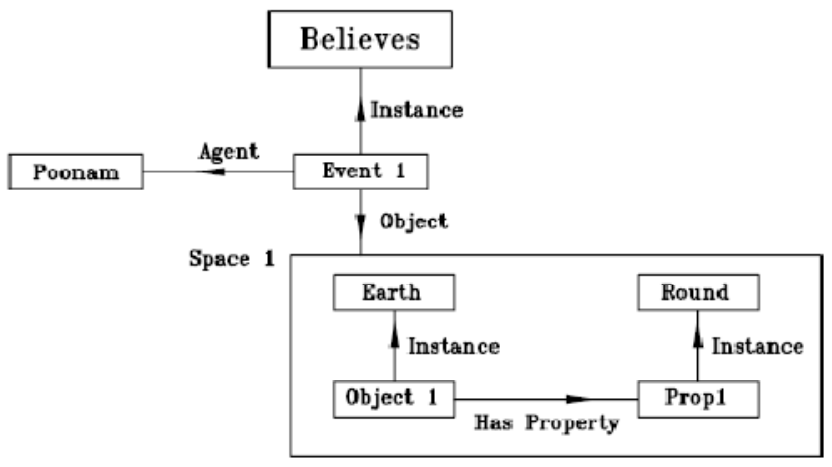

Fig.5 Partitioned Semantic Net [38]

Universal and existential quantifier can also be represent by the Partitioning semantic net. For ex, "Every sister knots the rakhee to her brother" in predicate logic. In predicate logic the sister $\mathrm{S}$ and rakhee $\mathrm{R}$ are represented as objects while the knot event is expressed by a predicate where as in case of semantic net the event is represented as an object of some complex object, i.e., the bite event is a situation which could be the object of some more complex event. Partitioning semantic net can also be used to represent universal quantifier. For ex "Every sister knots the rakhee to her brother" is represented in fig 6 [38]. Partitioning semantic net can also be used for complex quantifleations which involve nested scopes by using nesting space. 


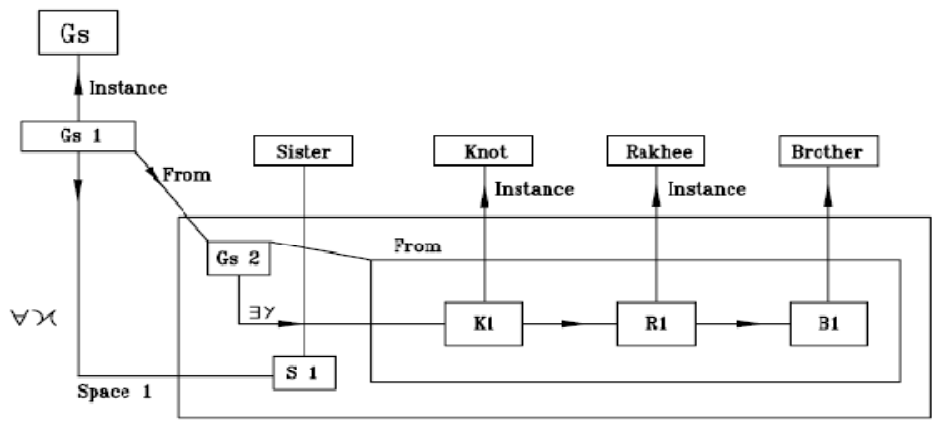

Fig.6 Represents Partitioned Semantic Net for Quantifiers [38].

\subsection{Scripts}

A variation in the theme of structured objects called scripts was devised by Roger Schank and his associates in 1973[3].It is an active type information which contain class of events in terms of contexts, participants and sub-events represented in the form of collection of slots or series of frames which uses inheritance and slots . Scripts predict unobserved events and can build coherent account from disjointed observations. Scripts basically describes the stereotypical knowledge i.e if the system in not given the information dynamically then it assumes the default information to be true Scripts are beneficial because real world events do follow stereotyped patterns as human beings use previous experiences to understand verbal accounts. A script is used for organizing the knowledge as it directs the attention and recalls the inference. They provide knowledge and expectations about specific events or experiences and can be applied to new situations. For example: "Rohan went to the restaurant and had some pastries". it was good now meaning derived from the above text one gets to know he got the pastries from the restaurant and that for eating and that was good. Script defines an episode with the known behavior and describes the sequence of events. The script consist the following.

- Current plans (Entry condition, Result)

- Social link(Track)

- Played roles,

- Scene.

- Probs.

- Anything indicating the behavior of the script in a given situation. An example of script for class room is shown in fig.7.

\begin{tabular}{|c|c|}
\hline \multicolumn{2}{|l|}{ Script Lecture Room } \\
\hline $\begin{array}{l}\text { Track: Class Room } \\
\text { Props: Table, Chair, Chock Board, Chock } \\
\text { Box, Duster, Lecture Stand, Projector. }\end{array}$ & $\begin{array}{l}\text { Entry Cond: Thas prepared lecture. } \\
\text { Thas Lecture Notes. } \\
\text { The class is open. } \\
\text { Thas attendance register. }\end{array}$ \\
\hline $\begin{array}{ll}\text { Roles: } & \mathrm{T}=\text { Teacher } \\
& \mathrm{S}=\text { Student }\end{array}$ & $\begin{array}{l}\text { Result: Thas imparted knowledge. } \\
\text { S: Acquired Knowledge. }\end{array}$ \\
\hline
\end{tabular}




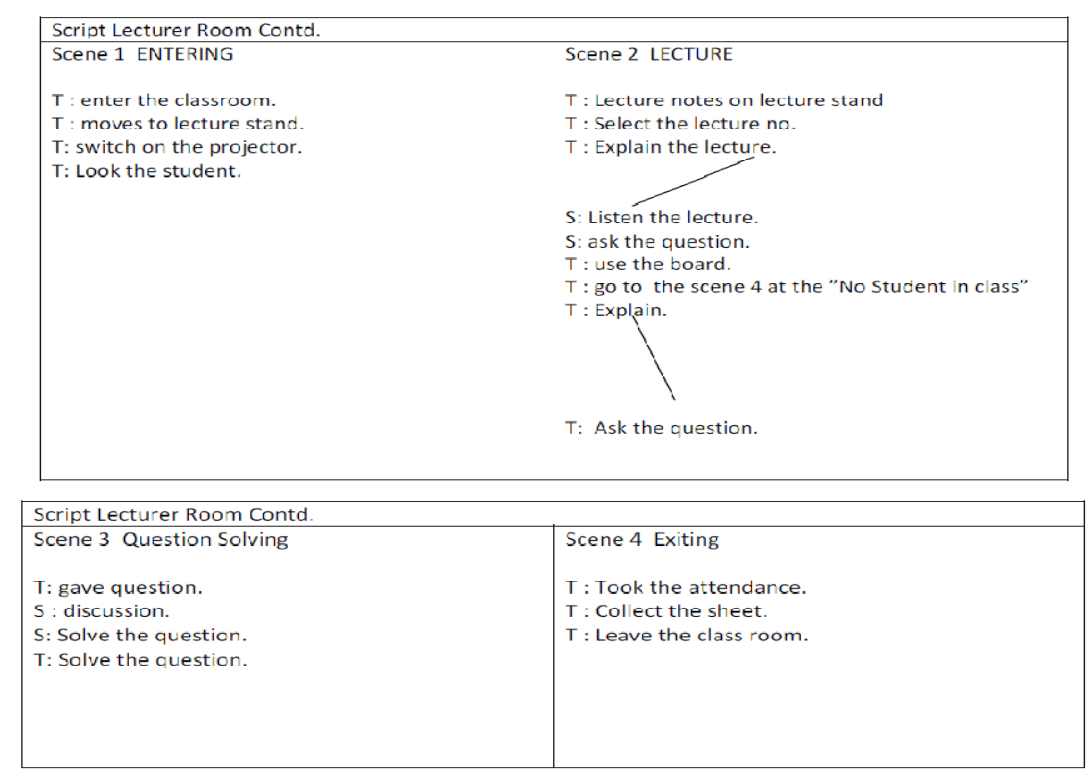

Fig.7 Script structure for class room.

Advantages of using scripts:

- Details for a particular object remain open and

- Reduces the search space.

Disadvantages

- Less general than Frames

- It may not be suitable for all kind of Knowledge

\section{HYBRID KNOWLEDGE REPRESENTATION TECHNIQUE}

Every knowledge representation technique has their own merits and demerits that depend on which type of knowledge we want to represent. To navigate the problem associated with single knowledge representation technique the hybrid knowledge representation came in picture.

The script and semantic net alone is a strong representation technique but still they have some disadvantages. The previous section consist the example of script for lecture room using that we are unable to get the detail like the teacher can teach one or more subject, Is a permanent or on contract basis ,student is a regular student or part time. Student opted one or many subject. Whereas using semantic net we can't represent the knowledge scene wise. Semantic net can't be use to represent the knowledge event by event. So to get all the knowledge from the system, integrated knowledge representation technique is used. The hybrid structure is shown in fig 8 . From script to semantic net two different directional link coming out that shows the link between the roles of script with the two different classes of semantic net. In the same way we can make the link between other roles and objects involve in scripts (scene wise) with the class and object in the semantic net. The unnamed link in semantic net shows the generalization for eg. Mode can be part time, full time and regular. 


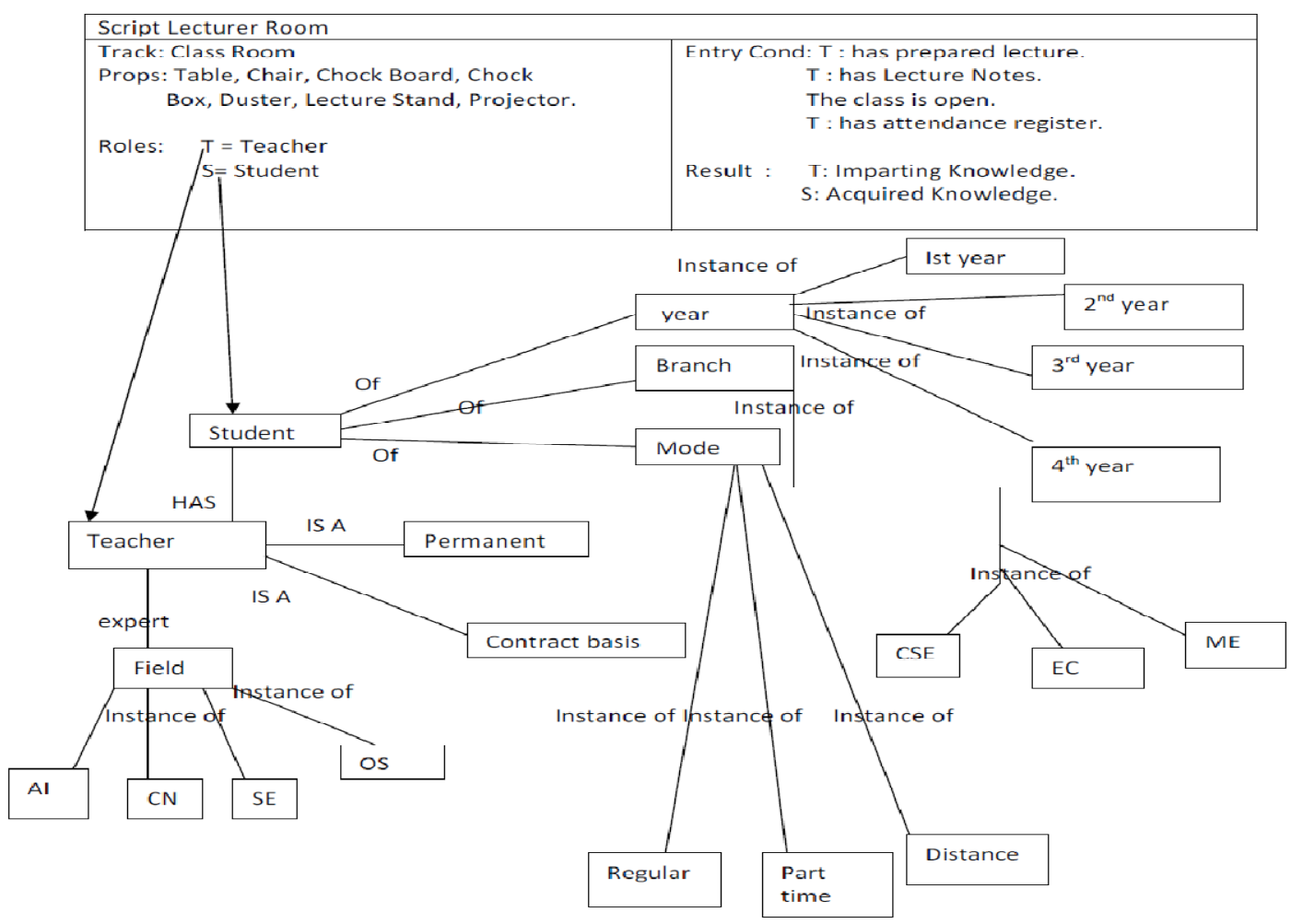

Fig 8. Hybrid Knowledge Representation technique.

As we know the input to the system is a sentence / paragraph/ story. Let us consider the another ex for representation.

Story 1. Ram Navami

Ram Navami is a Hindu festival that celebrates the birth of Lord Rama to king Dasharatha and queen Kaushalya of Ayodhya. Rama was an incarnation of Lord Vishnu. On this day, devotees of loard rama keep a fast. Houses are cleaned and temples are decorated. Offering of fruits and flowlers are made to the deity. It is customary to read massages from Ramayana.

The Hybrid representation for the above story is shown fig 9.

\subsection{STRENGTH OF HYBRID KNOWLEDGE REPRESENTATION TECHNIQUE.}

Human beings use past/previous learning \& senses to understand verbal communication and in actual real world events do follow stereotyped patters. Communication style of each one is different from other and it is quite often when relating events, do leave large amount of blanks/gaps or assumed details out of their communication. This may lead to miscommunication. In real life it is not easy to deal with a system that is not able to fill up the missing conversational features, whereas scripts can predict/ assume unobserved events. Scripts can fill the gaps created from incomplete/disjoined observations and can build a sequential information. Semantic net is best knowledge representation technique for representing non 
event based knowledge with its technical simplicity. Even non technology savvy can also extract information/ knowledge from the semantic net.

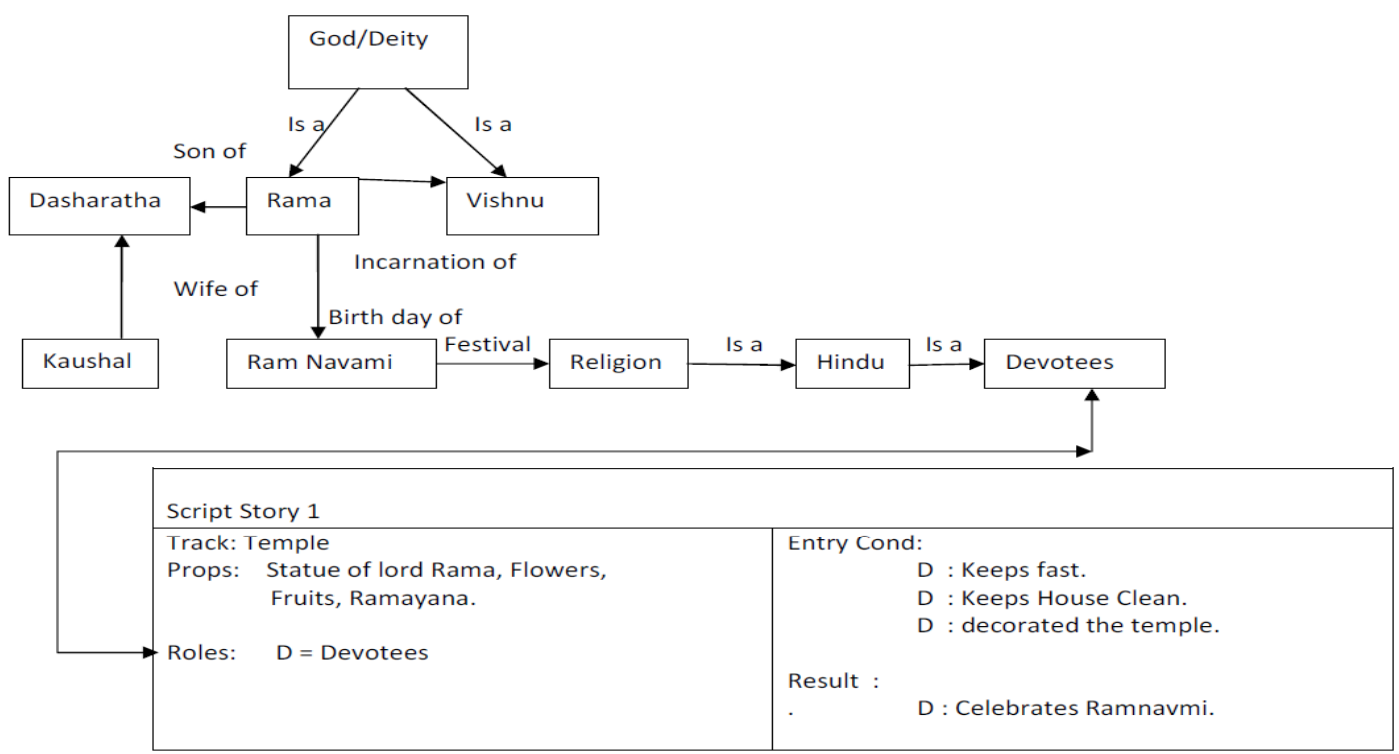

\begin{tabular}{|l|l|}
\hline \multicolumn{2}{|l|}{ Script Story1 Contd. } \\
\hline Scene 1 ENTERING & Scene 2 \\
D : Offering of fruits are made to the deity & Exit \\
D : Offering of flowers are made to the deity & \\
D : Open the Ramayana & \\
D : Reads the passages from Ramayana. & \\
\hline
\end{tabular}

Fig 9. Hybrid representation of story .

\section{CONClusion}

There are various knowledge representation schemes in AI. All KR techniques have their own semantics, structure as well as different control mechanism and power. Combination of two or more representation scheme may be used for making the system more efficient and improving the knowledge representation. We are trying to build the intelligent system that can learn itself by the query and have a power full mechanism for representation and inference. The semantic net and script are very powerful techniques in some respects so the aim is to take the advantage of these techniques under one umbrella. The comparison between various hybrid $\mathrm{KR}$ techniques is shown in table with the proposed one. 
International Journal of Computer Science \& Engineering Survey (IJCSES) Vol.3, No.4, August 2012

Table Comparison between hybrid knowledge representation techniques
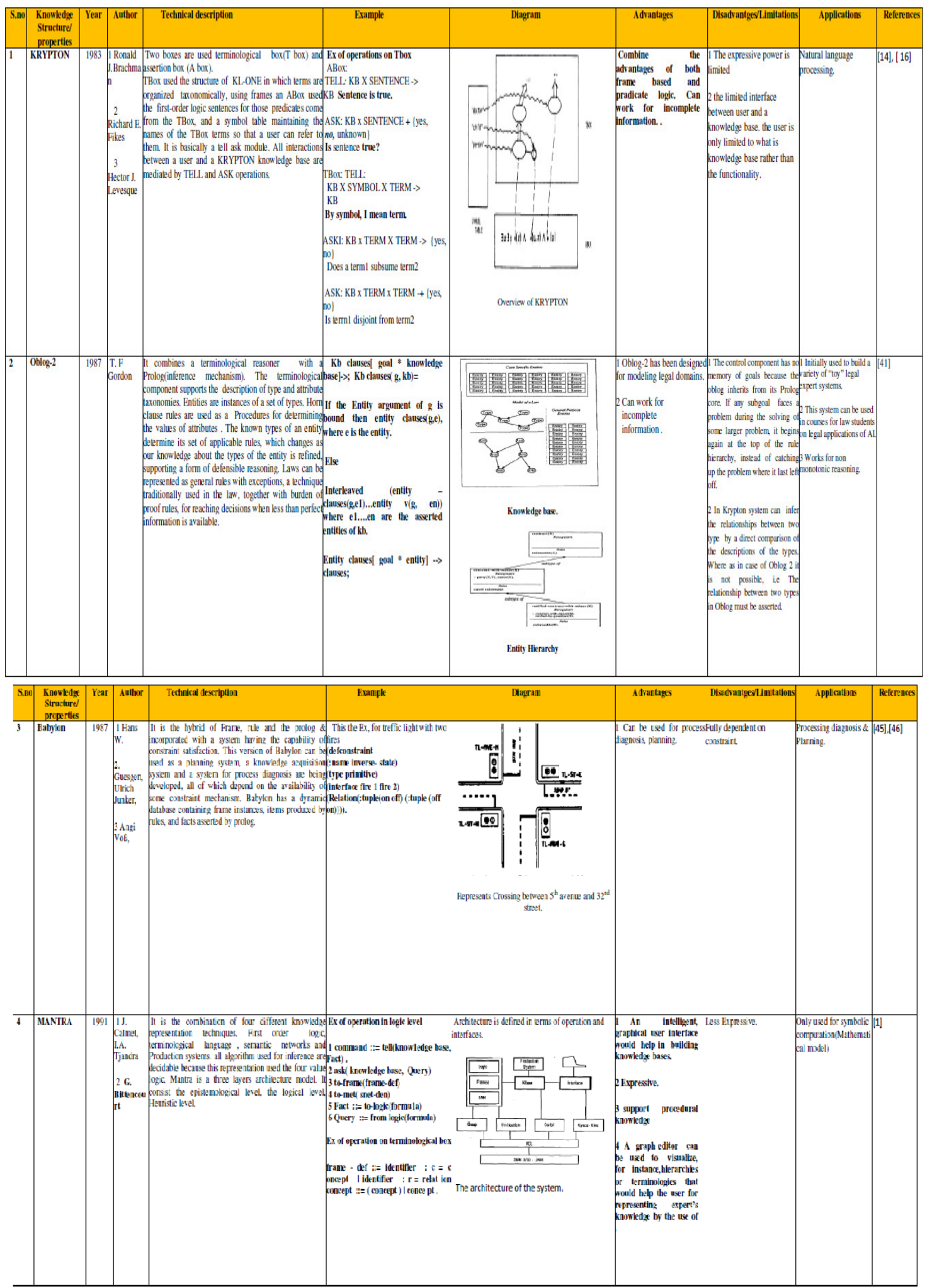
International Journal of Computer Science \& Engineering Survey (IJCSES) Vol.3, No.4, August 2012
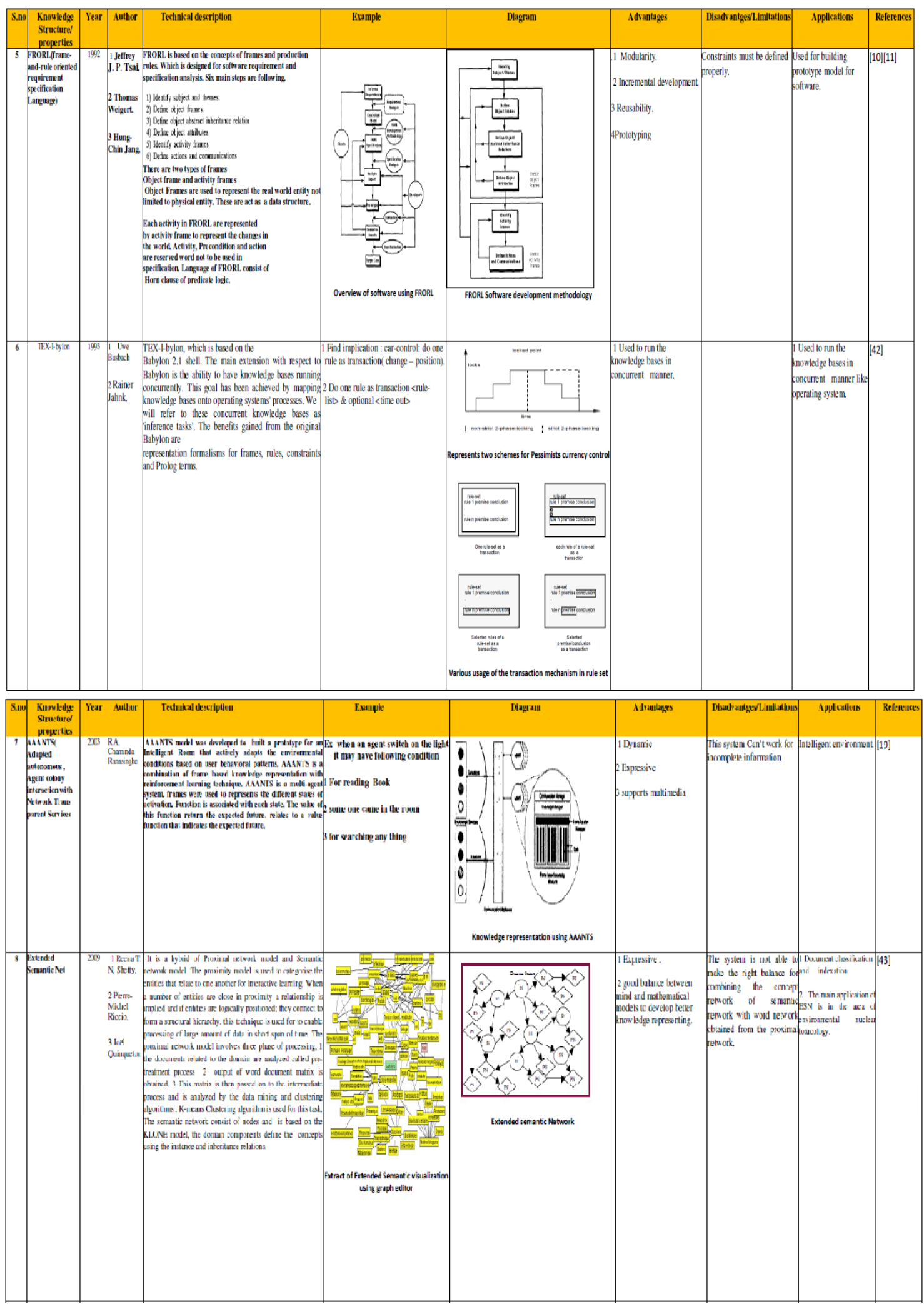
International Journal of Computer Science \& Engineering Survey (IJCSES) Vol.3, No.4, August 2012

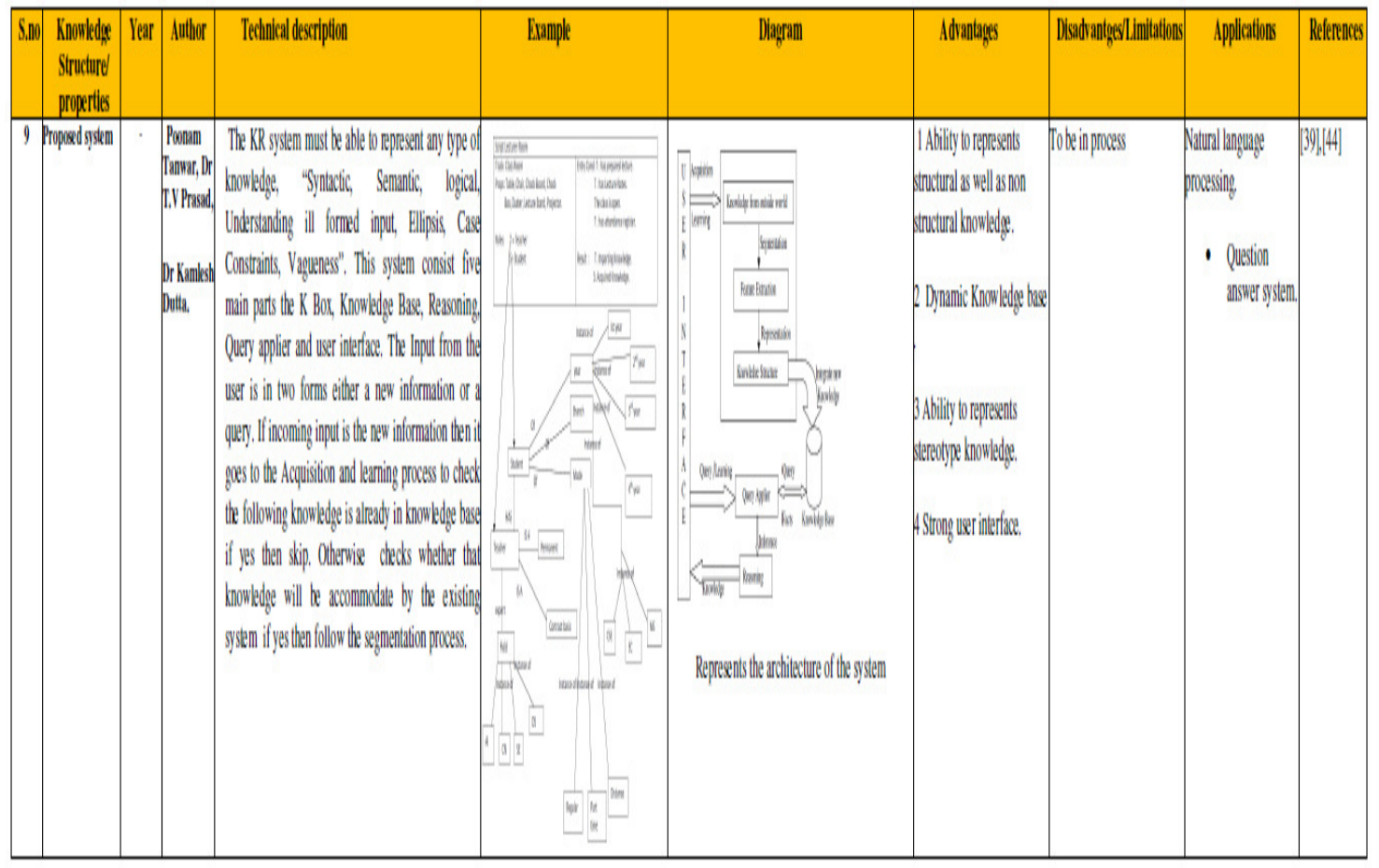

\section{REFERENCES}

[1] John F. Sowa, "Encyclopedia of Artificial Intelligence”, Wiley, 2nd edition, 1992.

[2] E. Rich and K. Knight, Artificial Intelligence, Second Edition, McGraw-Hill, 1991.

[3] Stuart Russell and Peter Norvig, Artificial Intelligence: A Modern Approach, Third edition, Prentice Hall, 2009

[4] R. Davis, H. Shrobe, and P. Szolovits, "What is a Knowledge Representation?", AI Magazine, 14(1):17- 33, 1993

[5] Brachman R, Levesque H, eds., "Readings in Knowledge Representation", Morgan Kaufman. 1985 .

[6] Stillings, Luger, "Knowledge Representation", Chapters 4 and 5, (1994), available at http://www.acm.org/crossroads/.www.hbcse.tifr.res.in/jrmcont/notespart1/node28.htm .

[7] G.J.P.M. Houben, "Knowledge representation and reasoning", Dutch Research Database, Period01 / 2002.

[8] R. A. Frost, "A Method of Facilitating the Interface of Knowledge Base System Components", University of Glasgow, Glasgow, UK, Computer Journal, 28(2): 112-116, 1985.

[9] Sharif, A M, "Knowledge representation within information systems in manufacturing environments", Brunel University Research Archive, 2004.

[10] Brewster, Christopher; O'Hara, Kieron; Fuller, Steve; Wilks, Yorick; Franconi, Enrico; Musen, Mark A, Ellman, Jeremy and Buckingham Shum, Simon, "Knowledge representation with ontologies: the present and future”. IEEE Intelligent Systems, 2004,. pp. 72-81. ISSN 15411672 . 
[11] James Allen, George Ferguson, Daniel Gildea, Henry Kautz, Lenhart Schubert, "Artificial Intelligence, Natural Language Understanding, and Knowledge Representation and Reasoning”, Natural Language Understanding, 2nd ed. (Benjamin Cummings, 1994).

[12] Syed S. Ali, and Lucja Iwanska, "Knowledge representation for natural language processing in implemented system”, Natural Language Engineering, 3:97-101, Cambridge University Press, 1997.

[13] Leora Morgenstern, “Knowledge Representation”, Columbia University, 1999, http://wwwformal.stanford.edu/leora/krcourse/.

[14] Han Reichgelt, "Knowledge Representation: An AI Perspective", Chapter 5 (Semantic Networks) and Chapter 6 (Frames).

[15] Frank van Harmelen, "Knowledge Representation and Reasoning "Vrije Universitetit Amsterdam, http://www.cs.vu.nl/en/sec/ai/kr.

[16] W.L. Kuechler, Jr, N. Lim, V.K. Vaishnavi, “A smart object approach to hybrid knowledge representation and reasoning strategies", Hawaii International Conference on System Sciences (HICSS '95).

[17] Shetty, R.T.N., Riccio, P.-M., Quinqueton, J., "Hybrid Model for Knowledge Representation", 2006. International Conference on Volume 1, pp. 355 - 361, 2006.

[18] Xiaoyi Chi, Ma Haojun, Zhao Zhen and Peng Yinghong, "Research on hybrid expert system application to blanking technology", Department of Plasticity Technology, National Die and Mold CAD Engineering Research Center, Shanghai Jiao Tong University, Shanghai 200030, PR China, 1999.

[19] W. Quesgen, U. Junker, A. Voss, “Constraints in Hybrid Knowledge Representation System” Expert Systems Research Group, F.R.G http://dli.iiit.ac.in/ijcai/IJCAI-87-VOL1/PDF/006.pdf.

[20] Bernhard Nebel, Kai Von Luck, Ibm Deutschland Gmbh, "Hybrid Reasoning in BACK", CiteSeerX - Scientific Literature Digital Library and Search Engine (US), 1988.

[21] Gary G. Hendrix, "Expanding the Utility of Semantic Networks through Partitioning", Artificial Intelligence Center, Stanford Research institute Menlo Park, California 94025.

[22] Fritz Lehmann, "Semantic networks", Parsons Avenue, Webster Groves, Missouri, U.S.A.

[23] Jeremy Gow, Lecture notes, Imperial College, London, www.doc.ic.ac.uk/ sgc/teaching/ v231/lecture4.ppt

[24] Tim Berner Lee, Chapter on "Semantic web road map", 1998, available at www.w3.org.

[25] Wai Khatib, "Semantic modeling and knowledge representation in Multimedia", available at ieeexlore.ieee.org, 1999.

[26] Lecture notes on Predicate logic. http://www.cs.odu.edu/ toida/nerzic/content/logic/pred_logic/inference/infer_intro.html

[27] Presentation on "Knowledge representation", available at http://www.doc.ic.ac.uk/ $\sim$ sgc/teaching/v231/lecture4.ppt

[28] Presentation on "Knowledge representation techniques, available at http://www.scribd.com/doc/6141974/semantic-networks-standardisation

[29] Web document on "Predicate logic history", available at http://www.cs.bham.ac.uk/research/projects/poplog/computers-and thought/chap6/node5.html

[30] Web document on "Introduction to Universal semantic net", available at http://sempl.net/ 
[31] Lecture notes on "knowledge representation misc psychology and languages for knowledge representation, available at http://misc. thefullwiki.org/Knowledge_representation

[32] Lecture notes on frame knowledge representation technique, available at http://userweb.cs.utexas.edu/users/qr/algy/algy-expsys/node6.html

[33] Presentation on "Knowledge representation using structured objects", available at www.freshtea.files.wordpress.com/2009/.../5-knowledge-representation.ppt -

[34] Shyh-Kang Jeng, Lecture notes on "Knowledge representation", available at www.cc.ee.ntu. edu.tw/ skjeng/Representation.ppt.

[35] Presentation on "Knowledge representation and rule based systems", available at www.arun555mahara.files.wordpress.com/2010/02/knowledge-representation.ppt.

[36] Presentation on "Various knowledge representation techniques, available at http://www.ee.pdx.edu/ mperkows/CLASS_ROBOTICS/FEBR-19/019.representation.ppt

[37] PPT and lecturer notes,http://people.dbmi.columbia.edu/homepages/wandong/KR/krglossary.html\#default reasoning.

[38] Poonam Tanwar, Dr. T.V Prasad, Dr.Mahendra. S. Aswal,"Comparative Study of Three Declarative Knowledge Representation Techniques",(IJCSE) International Journal on Computer Science and EngineeringVol. 02, No. 07, 2010, 2274-2281.

[39] Poonam Tanwar, Dr. T. V. Prasad, Dr. Kamlesh Datta," An Effective Knowledge base system Architecture and issues in representation techniques", International Journal of Advancements in Technology http://ijict.org/ ISSN 0976-4860.

[40] Lecturer notes on Knowledge Representation Available at http://www.scribd.com/doc/13599253/Knowledge-Representation.

[41] Thomas F. Gordon," Oblog-2 A Hybrid Knowledge Representation System for Defeasible Reasoning”, ACM O-89791,pp 231-239.1987.

[42] Josef Meyer and Robert Dale," Building Hybrid Knowledge Representations from Text", Josef Meyer and Robert Dale Language Technology Group ,Division of Information and Communication Sciences, Macquarie University, Sydney, NSW 2109.

[43] Reena T.N.Shetty,Pierre Michel Riccio, Joel Quinqueton,"Extended Semantic ,Network For Knowledge Representation ",published in Information Reuse and Integration, France, "IEEEIRI‘, vol1,2009.

[44] Presentation on "Various knowledge representation techniques, available at http://www.ee.pdx.edu/ mperkows/CLASS_ROBOTICS/FEBR-19/019.representation.ppt

[45] W. Quesgen, U. Junker, A. Voss, "Constraints in Hybrid Knowledge Representation System" Expert Systems Research Group, F.R.G http://dli.iiit.ac.in/ijcai/VOL1, IJCAI,1987.

[46] Rathke, C., "Object-oriented programming and frame-based knowledge representation", 5th International Conference, Boston, 1993. 


\section{Authors 1}

Poonam Tanwar received her B.Tech, M.Tech degree in Computer Science \& Engg from Maharishi Dayanand University Haryana. Prsuing P.hd From Uttarakhand Technical University Dehradun( UTU). She has over 10 years of experience in teaching. Currently she is Assit Professor At Lingaya's University, Faridabad, Haryana, India. She has 20 papers to his credit. Her areas of Interest includes artificial intelligence, Computer graphics, Theory of computation, Soft Computing. She is member of IEEE.

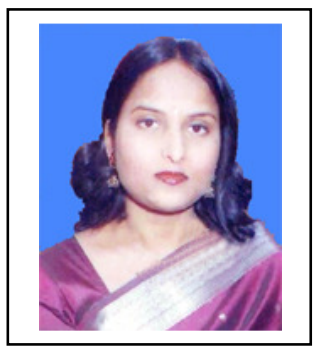

\section{Authors 2}

Dr. T. V. Prasad received his master's degree in Computer Science from Nagarjuna University, AP India and a doctoral degree from Jamia Milia Islamia University, New Delhi, India.. He has over 17 years of experience in industry and teaching. He has worked as Deputy Director in the Bureau of Indian Standards, New Delhi. Currently he is Professor and Dean academic. At Lingaya's University, Faridabad, Haryana, India. He has 100 papers and three books to his credit. His areas of interest include bioinformatics, artificial intelligence, consciousness studies, computer organization and architecture. He is a member of

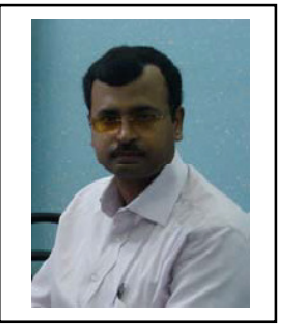
reputed bodies like ISRS, CSI, APBioNet, etc.

\section{Authors 3}

Dr. Kamlesh Dutta is working as Associate Professor in the Department of Computer Science \& Engineering in National Instituteof Technology, Hamirpur (India). 